\title{
EXCISION OF THE BREAST THROUGH TRANSVERSE INCISIONS.
}

\author{
By HAROLD DODD, Ch.M. (L'pool), F.R.C.S. (Eng.)
}

(Surgeon to the King George Hospital, Ilford; Assistant Surgeon to the London Homoopathic Hospital, etc.).

The conventional diagonal elliptical incision for mastectomy and for the radical excision of carcinoma of the breast has given the writer dissatisfaction for several years, particularly from the æsthetic point of view. The scar usually stretches laterally and becomes unsightly, whilst in the region of the axilla it. contracts and thickens forming an unyielding cord which tends to limit abduction and raising the arm above the head. Again a certain number of these cases heal slowly; whilst in the radical excision for carcinoma, when adequate skin is removed, there is difficulty in closing the flaps and frequently (about I in 3 in the writer's practice) there is a variable amount of necrosis of the skin edges.

The mature breast resolves itself into a dependant pouch of skin, subcutaneous tissue and mammary gland, which is suspended transversely from the anterior and lateral walls of the thorax. In view of this it seems right to perform the excision through these " normal" folds rather than in almost the opposite direction, i.e., diagonally which is general practice.

Amputation of the breast through a transverse incision is not new but so far as the writer is aware it is not detailed in a British text-book. Steward described mastectomy through a transverse incision in the "Annals of Surgery" in August, I9I5, Babcock mentions it in his book and it is also described in Nelson's Living Loose Leaf System of Surgery (American).

A factor which may have discouraged excision through the normal creases is that the "fold" character of the breast disappears when patients lie supine and still more so when the arm is abducted to the position usual for breast operations. Another objection is that the area of skin enclosed in the transverse lines is so large that it would seem the resulting wound would be difficult to close.

\section{The Incisions.}

Since 1936 the writer has practised mastectomy through transverse incisions. With the patient in a sitting position, the breast is so held that the limits of skin which completely contain the gland can be carefully outlined with Bonney's crystal violet. When the fingers holding the gland are pressed together on these lines, they are separated apparently only by subcutaneous tissue, and there is no tension on the skin above and below the breast. A few flat firm breasts will not lend themselves to this procedure and here an eye for the right amount of skin to remove is necessary.

Figs. I and 2 (Art Plate) show a breast outlined in the upright position. Fig. 3 (Art Plate) reveals the considerable and surprising spread which occurs when the patient lies down. It will probably be conceded that the excision of such an area of skin would appear to render closure of the wound difficult or improbable. The operation was first performed on a patient with an average pendulous breast. There was a bloody discharge from the nipple which proved to be due to a duct papilloma. The incisions were made on the line of Figs. I and 2. The flaps were under-cut superiorly almost to the clavicle, inferiorly to the costal margin, to the midline and laterally to the anterior border of latissimus dorsi. The circumference of this outlined area was deepened to the deep fascia and the gland was peeled 
from pectoralis major and serratus magnus. Fig. 4 (Art Plate) shows the resulting wound with the skin ready for suturing. In Fig. 5 (Art Plate) the wound is closed, no difficulty was experienced. The suturing was assisted by raising the head and shoulders and bringing the arm to the side of the body. Fig. 6 (Art Plate) illustrates the removed specimen (it is upside down) and the reader will notice the transverse measurement of excised tissue is $10 \frac{3}{4}$ in. Thus, the entire breast as detailed by the anatomist was removed, and Io days later the healing was normal and the mobility of the arm perfect. Fig. 7 (Art Plate) was the result four months afterwards, the appearance and function of the arm were favourably commented on.

The reader may question the need for this complete anatomical excision of the breast for conditions like persistent pain or a duct papilloma. The following case is one of several which emphasize the importance of a thorough operation:-

In 1936 a patient had a central mastectomy for pain; temporary relief followed. A year later a carcinoma developed in the unremoved tail of the breast, necessitating the radical operation. In 12 months a recurrence appeared in the skin and also in the opposite breast.

The planning of the procedure calls for more care than the conventional incisions but the cosmetic result is very good.

With increasing experience the writer is using this method in suitable cases for the radical excision for carcinoma; the results have been entirely satisfactory.

Conclusion.

The operation of mastectomy through transverse incisions is detailed. 


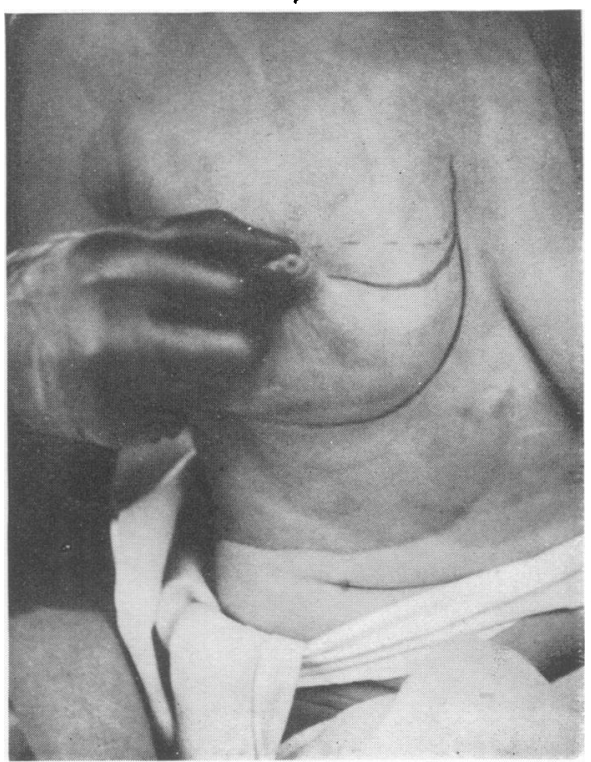

FIG. 2.-Excision of the breast. The lower incision.

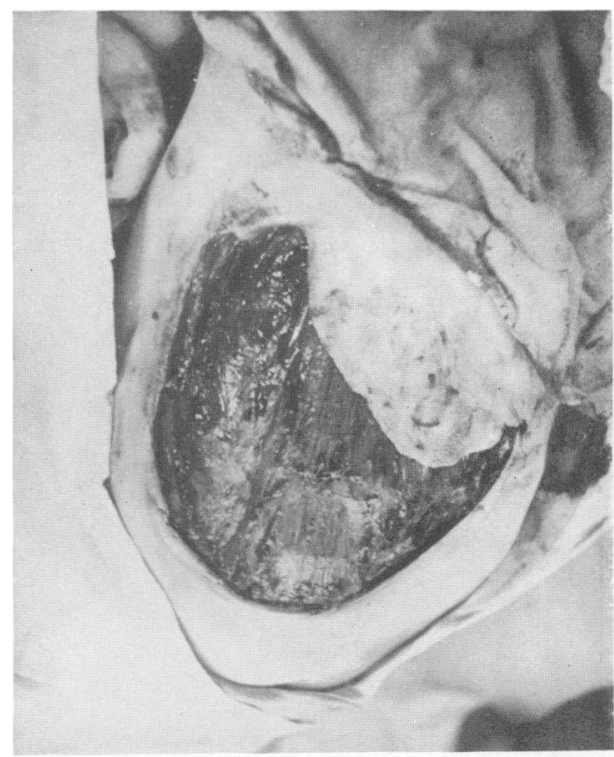

FIG. 4.-Excision of the breast. The flaps ready for suturing. 


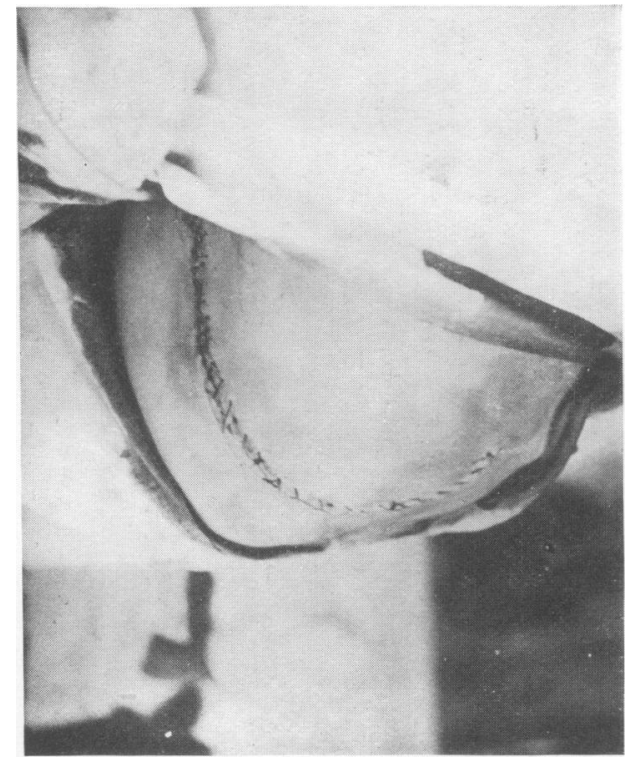

FIG. 5.-Excision of the breast. The wound closed.

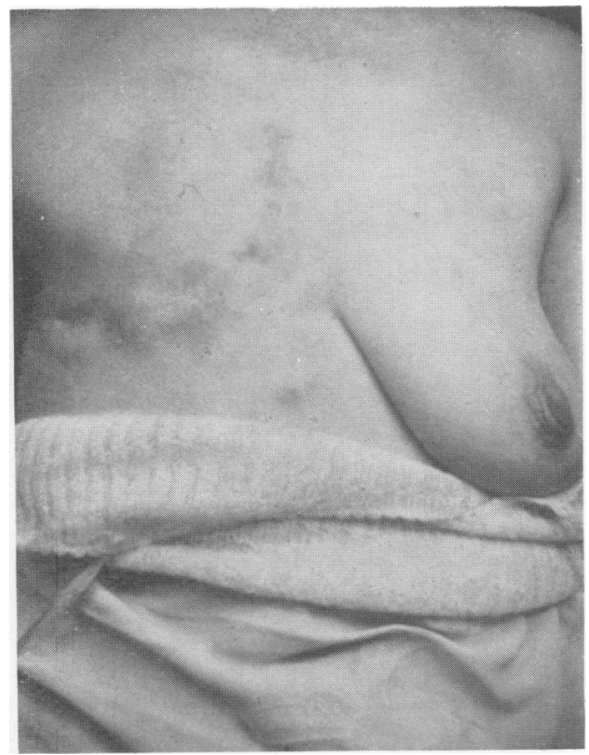

FIG. 7.-Excision of the breast. Six months after operation.

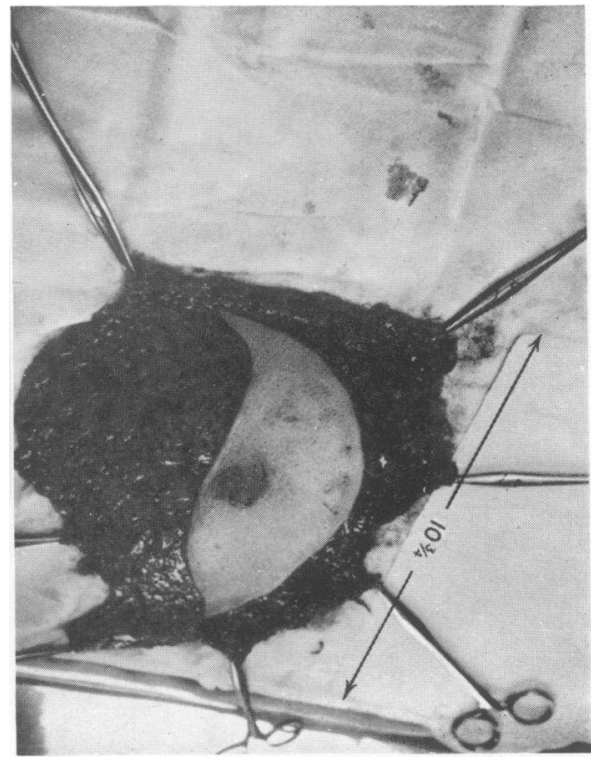

FIG. 6.-Excision of the breast. The specimen, note the measurement.

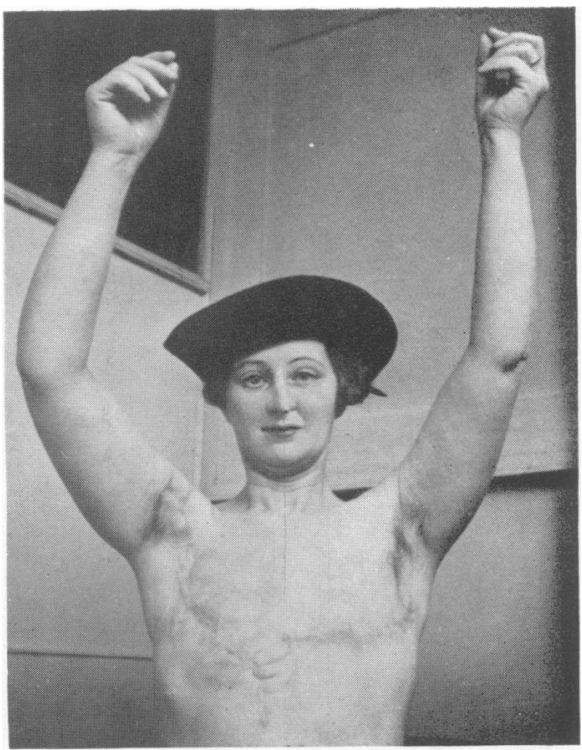

FIG. 8.-Bi-lateral excision of the breasts for carcinoma. The right side through the conventional incision ; the left a year later through the transverse incision. Note the improved mobility. 